\title{
Utilization of lower leg compression technique for reducing spinal induced hypotension, and related risks for mothers and neonates during cesarean delivery
}

\author{
Aziza Ibrahim Mohamed ${ }^{* 1}$, Rizk Abdel Hakeem Elazhary ${ }^{2}$, Rehab Mohamed Abdelhady ${ }^{1}$, BasmaRabieeAbd El Sadek ${ }^{1}$, \\ Khadiga Mohamed Said ${ }^{1}$ \\ ${ }^{1}$ Faculty of Nursing, Benha University, Benha, Egypt \\ ${ }^{2}$ Faculty of Medicine, Benha University, Benha, Egypt
}

Received: November 20, 2015

Accepted: January 10, 2016

Online Published: February 2, 2016

DOI: $10.5430 /$ jnep.v6n7p11

URL: http://dx.doi.org/10.5430/jnep.v6n7p11

\begin{abstract}
Background: Hypotension during spinal anesthesia for caesarean delivery is the most common clinical problem. It has a risk factor for adverse maternal and fetal events. This study aimed to evaluate the effect of the lower leg compression technique for reducing spinal induced hypotension risks for mothers and neonates during cesarean delivery.

Methods: An experimental design was adopted in the current study. The study was conducted at the cesarean delivery unit in Benha University Hospital during the period from November 2013 to October 2014. A systematic random sample was detected according to the study formula based to be 768 of women underwent elective cesarean delivery with spinal anesthesia to be equally allocated into in two groups: leg compression and control group. Pre-hydration and anesthetic technique standardized protocol was followed. Hypotension was defined as a decrease in any mean arterial pressure (MAP) measurement by more than $20.0 \%$ of the baseline. Three tools were used in the current study to collect the necessary data: structured interviewing questionnaire sheet, maternal hemodynamic and signs of hypotension record, and neonatal outcomes assessment sheet.

Results: A highly statistically significant difference was found between the leg compression and the control group regarding the mean arterial pressure and neonatal acidosis, as hypotension of the systolic arterial pressure, the diastolic arterial pressure, and the mean arterial pressure was affected a greater percentage of women at the control group than those in the leg compression. In addition neonatal Apgar scores were high among study leg compression group as compared with control group.

Conclusions: The lower leg compression for women under elective cesarean with spinal anesthesia is an effective measure to reduce spinal induced hypotension during cesarean delivery. Recommendations: The lower leg compression during cesarean delivery should be included in the maternal hospitals protocol for reducing spinal induced hypertension and related risks for mothers and neonate during cesarean delivery.
\end{abstract}

Key Words: Lower leg compression, Mothers and neonatal risks, Cesarean delivery, Spinal hypotension

\section{INTRODUCTION}

Spinal anesthesia is the most common anesthetic technique for a caesarean delivery. It helps to avoid risks of general anesthesia and facilitate an effective postoperative pain relief.
Spinal hypotension is the commonest clinical problem of spinal anesthesia that is usually accompanied by nausea and vomiting. Severe spinal hypotension can result in serious risks to the mother, including loss of consciousness, and to Egypt.

Published by Sciedu Press 
the neonate, such as lack of oxygen and brain damage. ${ }^{[1]}$

Spinal induced hypotension caused by a reduction in systemic vascular resistance is physiologically compensated by an increase in cardiac output (CO). However, a high level of spinal block can inhibit the cardio accelerator fibers leading to a fall in the heart rate, and hence the $\mathrm{CO}$, thus, instead of a compensatory increase, $\mathrm{CO}$ usually decreases. ${ }^{\text {[2] }}$ The combined effect of reduced $\mathrm{CO}$ and decreased systemic vascular resistance accounts for the high incidence of hypotension after spinal anesthesia. Uterine blood flow is pressure dependent, as there is no auto regulation of the placental bed. ${ }^{[3]}$ As a consequence, it prolonged maternal hypotension is detrimental to the fetus and is also frequently associated with maternal nausea and vomiting. Brief episodes of maternal hypotension can lower the fetal Apgar scores, and prolong fetal acidosis and the time to sustained respiration. ${ }^{[4]}$

Numerous prophylactic strategies have been tested to prevent spinal induced hypotension. Very few have been shown to be partially effective: colloid fluid pre-loading, crystalloid co-loading, vasopressors, and lower limb compression. ${ }^{[5-7]}$ However, the incidence of hypotension can be reduced, but cannot be eliminated. Most studies use doses of spinal bupivacaine of 9-15 mg. Many authors suggested that, lowering the spinal dose to less than $7.5 \mathrm{mg}$ of bupivacaine intrathecal might reduce the incidence and the severity of hypotension. ${ }^{[8-10]}$

Moreover, several studies had been conducted to manage hypotension problem in the Cochrane review, 75 studies were included. Only eight of the studies included describing adequate randomization, and only 28 were blinded. Several interventions reduced the incidence of hypotension, but no single technique could effectively abolish hypotension. ${ }^{[1-13]}$

\subsection{Significance of the study}

Spinal hypotension is the commonest clinical problem of spinal anesthesia during cesarean delivery. It is usually accompanied by maternal and neonatal risks. Maternal risks may include nausea, vomiting, and serious risks including loss of consciousness. Neonatal risks may include lack of oxygen and brain damage. The incidence of hypotension during spinal anesthesia for caesarean section is estimated to be as high as $80.0 \%$. So, preventing hypotension during spinal anesthesia for cesarean section has been referred as "Holy Grail" in obstetric. ${ }^{[14]}$ Therefore, the aim of the present study was to evaluate the effect of lower leg compression on reducing spinal induced hypotension during cesarean section and its related risks for mothers and neonates.

\section{Operational definition}

Hypotension was defined as a decrease in any mean arterial pressure (MAP) measurement by more than $20.0 \%$ of the baseline.

\subsection{Aim of the study}

The aim of this study was to evaluate the effect of the lower leg compression technique for reducing spinal induced hypotension risks for mothers and neonates during cesarean delivery.

\subsection{Research hypothesis}

Utilizing lower leg compression during cesarean delivery will reduce maternal hypotension and decrease neonatal risk for acidosis.

\section{MATERIAL AND METHODS}

\subsection{Research design}

An experimental design was used in the present study to fulfill the aim of the present study.

\subsection{Setting}

This study was carried out at the cesarean delivery operating room at obstetrical and gynecological department affiliated to Benha University Hospital.

\subsection{Study sampling}

Type: A systematic random sample technique was used to select the women under the study. As each woman who had an odds number at cesarean operational delivery list was recruited in the present study.

Size: A total of 384 women with cesarean delivery were recruited in each of both the leg compression and the control group. To study the effect of the leg compression on reducing spinal hypotension during cesarean delivery, the sample size was calculating utilizing the following formula by Fisher et al.: $n=t^{2} \times p(1-p) / m^{2}$. That depend on the Description/Explanation of the formula: $n=$ required sample size; $t=$ confidence level at 95\% $(t=1.96) ; p$ $=$ estimated prevalence rate (the quoted incidence of hypotension [a key determinant of fetal wellbeing] ranges from $8.0 \%$ to $80.0 \%$ depending on whether prophylaxis is given or not. Since we do not routinely give prophylactic ephedrine or any other vasopressor and we have no studies previously done to determine the local prevalence rate, we shall choose $50.0 \%$ ); $m=$ margin of error at $5.0 \%$ (standard value $=0.05)$. Therefore $=1.96^{2} \times 0.5(1-0.5) / 0.05^{2}=$ $(3.8416 \times 0.5 \times 0.5) / 0.0025=384$ women for the leg compression group, so the researcher need to had the same sample size for the control group. 


\subsubsection{Inclusion criteria}

(1) Age ranged from 19 to 40 years old.

(2) Elective cesarean delivery.

(3) Single fetus.

(4) Free from any pregnancy related complications.

(5) Gestational age $\geq 37$ wks.

(6) Height between $130 \mathrm{~cm}$ and $180 \mathrm{~cm}$.

\subsubsection{Exclusion criteria}

(1) Women with history of deep venous thrombosis of their lower limbs.

(2) Women with superficial thrombophlebitis of their legs.

(3) Women with allergic reaction developed to the local anesthetic before.

(4) Morbid obese women with body mass index more than $30 \mathrm{~kg} / \mathrm{m}^{2}$.

\subsection{Tool of data collection}

Three tools were used for data collection:

\subsubsection{Structured interviewing questionnaire sheet}

It was developed by the researcher, and was used to collect the personal data such as: age, educational level, residence, weight, height, and gestational age, etc.

\subsubsection{Maternal hemodynamic and signs of hypotension record}

It was constructed by the researcher after reviewing related literatures to record the maternal hemodynamic data (physiological measurements were done using automated machines), and signs of maternal hypotension such as: nausea and vomiting.

\subsubsection{Neonatal outcomes assessment sheet}

It was developed by the researcher to record the umbilical arterial blood PH, umbilical venous blood $\mathrm{PH}$, and Apgar score at 1 st and 5 th minutes.

\subsection{Content validity}

Content validity was tested by five experts in the field of maternity nursing, obstetric medicine, and neonatal medicine staff. The questionnaire was modified according to the panel's judgment on clarity of sentences and appropriateness of content. The percentage of consensus among experts regarding the structured interviewing questionnaire was $96.0 \%$, maternal hemodynamic and signs of hypotension record was 97.0\%, and neonatal outcomes assessment sheet was $98.0 \%$.

\subsection{Pilot study}

It was conducted on $10.0 \%$ of the total study sample to evaluate the feasibility, clarity, and reliability of the tool. It revealed that, test-retest reliability and internal consistency for the interviewing questionnaire was $(r=0.91$ and $\alpha=$ 0.93 respectively). Maternal hemodynamic and signs of hypotension record related Cronbach's alpha were $(\alpha=0.93)$. In addition, Cronbach's alpha for neonatal outcomes assessment sheet was 89.0. The samples of the women included in the pilot study were excluded from the main study sample.

\subsection{Ethical considerations}

The present study was conducted under the approval of the Faculty of Medicine Ethics Committee, Benha University. Participants were given explanations about the purpose of the study, and they were also informed that they could withdraw from the study at any time before the completion of the study without giving any reasons. Participants who agreed to complete in this study were asked to sign a consent form. Confidentiality of participants' information was assured and the data were accessed only by the investigators involved in the study.

\subsection{Field of work}

Data were collected from the beginning of November 2013 till the beginning of October 2014. Immediately after the ethical approval was obtained, all mothers signed an informed consent after full explanation of spinal anesthesia with respect to lumbar spinal puncture, the local anesthetic used in this study, and the possible complications that could occur during the study.

All mothers received $500 \mathrm{ml}$ of lactated ringer solution as preloading fluid, and then all the patients received spinal anesthesia at levels between L3-L4 or L4-L5 interspaces. All mothers were canulated in the left antecubital vein with $16 \mathrm{G}$ intravenous catheters (cannula), and monitored by noninvasive blood pressure, pulse oximeter, and electrocardiography.

While in the sitting position giving hyperbaric bupivacaine $0.5 \% 2.5 \mathrm{ml}(12.5 \mathrm{mg})$, and then the mothers were put in the supine position with a $15^{\circ}-30^{\circ}$ left lateral tilt just after receiving the anesthesia. The control group had the ordinary nursing care. For the leg compression group compression knee stockings were applied, a thigh-length gradient compression stocking was used, the compression pressure level was between 15 and $20 \mathrm{mmHg}$. The compression knee stockings were applied until the end of cesarean delivery.

For both leg compression and control group the following hemodynamic measures including systolic arterial pressure, diastolic arterial pressure and mean arterial pressure (SAP, DAP, MAP) were recorded at baseline and every 5 minutes after spinal anesthesia until the end of cesarean delivery. The baseline hemodynamic variables measures were defined as the average of three consecutive recordings with less than $10.0 \%$ variation over 10 mins before pre-hydration. 
In the present study, hypotension was defined as a decrease in any MAP measurement by more than $20.0 \%$ of the baseline. Immediately after delivery, for both groups, the umbilical arterial and venous blood samples were collected in heparinized syringes and taken to the laboratory within one hour of collection and analyzed for blood gases and $\mathrm{pH}$, as a measure to diagnose the neonatal acidosis. Apgar scores were also noted at the first and after the fifth minutes.

\section{RESUlts}

A total of 768 women were randomly selected in a systematic manner. Mothers with odds numbers within the list of cesarean operational delivery and met the criteria of inclusion of the present study was recruited in the present study, and they were randomly allocated into two groups; study and control group. There was no statistical significant difference between study and control group regarding their personnel characteristics. The findings of the present study support the study hypothesis that utilizing lower leg compression during cesarean delivery reduced maternal hypotension and decrease neonatal risk for acidosis as hypotension of the systolic arterial pressure, the diastolic arterial pressure, and the mean arterial pressure was affected a greater percentage of women at the control group than those in the leg compression group with a highly statistically significant difference between both groups.

Table 1 presents the general characteristics of mothers under the study. It was observed that, the mean age were $(25.26 \pm$ $2.90 \& 25.18 \pm 2.99$ years) in the leg compression and the control groups respectively. In addition, the same table manifests that, $65.9 \%$ \& $65.4 \%$ of mothers had a secondary level of education in the leg compression and the control group respectively. Concerning residence, it was found that, the majority of mothers in both groups were residing in urban areas. Furthermore, this table illustrates that, $67.7 \%$ \& $72.1 \%$ were housewives in the leg compression and the control groups respectively. Moreover, this table reveals that, there were no statistically significant difference between both groups regarding the mean score of height, weight, and body mass index.

Table 2 displays the characteristics of the current cesarean delivery, it was observed that there was no statistical significant difference between the leg compression and the control group regarding numbers of cesarean delivery, times of cesarean delivery, and estimated gestational age.

Table 1. Distribution of general characteristics of mothers under study

\begin{tabular}{|c|c|c|c|c|c|c|c|}
\hline \multirow{2}{*}{ Variable } & \multicolumn{2}{|c|}{$\begin{array}{l}\text { Leg compression } \\
\text { group }(\mathrm{n}=384)\end{array}$} & \multicolumn{2}{|c|}{$\begin{array}{l}\text { Control group } \\
(\mathrm{n}=384)\end{array}$} & \multicolumn{2}{|c|}{ Analytic tests } & \multirow{2}{*}{$p$ value } \\
\hline & No & $\%$ & No & $\%$ & Chi square & Independent $t$ test & \\
\hline \multicolumn{8}{|l|}{ Age in years } \\
\hline $20-$ & 116 & 30.2 & 135 & 35.2 & \multirow{4}{*}{2.14} & & \multirow{4}{*}{$>.05$} \\
\hline $25-$ & 234 & 60.9 & 218 & 56.8 & & & \\
\hline $30-$ & 34 & 8.9 & 31 & 8.1 & & & \\
\hline Mean \pm SD & \multicolumn{2}{|c|}{$25.26 \pm 2.90$} & \multicolumn{2}{|c|}{$25.18 \pm 2.99$} & & & \\
\hline \multicolumn{8}{|c|}{ Educational qualification } \\
\hline Illiterate & 27 & 7.0 & 24 & 6.3 & \multirow{4}{*}{.400} & & \multirow{4}{*}{$>.05$} \\
\hline Read and write & 22 & 5.7 & 25 & 6.5 & & & \\
\hline Secondary educational & 253 & 65.9 & 251 & 65.4 & & & \\
\hline University education & 82 & 21.4 & 84 & 21.9 & & & \\
\hline \multicolumn{8}{|l|}{ Residence } \\
\hline Rural & 52 & 13.5 & 68 & 17.7 & \multirow[t]{2}{*}{2.52} & & \multirow[t]{2}{*}{$>.05$} \\
\hline Urban & 332 & 86.5 & 316 & 82.3 & & & \\
\hline \multicolumn{8}{|l|}{ Occupational condition } \\
\hline Working & 124 & 32.3 & 107 & 27.9 & \multirow[t]{2}{*}{1.78} & & \multirow[t]{2}{*}{$>.05$} \\
\hline House wife & 260 & 67.7 & 277 & 72.1 & & & \\
\hline Body weight & \multicolumn{2}{|c|}{$75.44 \pm 14.18$} & \multicolumn{2}{|c|}{$75.20 \pm 14.53$} & & $.226 *$ & $>.05$ \\
\hline Length & \multicolumn{2}{|c|}{$163.36 \pm 8.31$} & \multicolumn{2}{|c|}{$163.09 \pm 8.67$} & & $.437 *$ & $>.05$ \\
\hline Body mass index & \multicolumn{2}{|c|}{$28.25 \pm 5.58$} & \multicolumn{2}{|c|}{$28.29 \pm 5.87$} & & $.097 *$ & $>.05$ \\
\hline
\end{tabular}

$* p$ value indicated by independent $t$ test Group Statistics. 
Table 2. Distribution of characteristics of the present cesarean delivery of mothers under study

\begin{tabular}{|c|c|c|c|c|}
\hline \multirow{2}{*}{ Variable } & Leg compression group $(n=384)$ & Control group $(n=384)$ & \multirow{2}{*}{$\begin{array}{l}\text { Independent } \\
t \text { test }\end{array}$} & \multirow{2}{*}{ p value } \\
\hline & Mean \pm SD & Mean \pm SD & & \\
\hline No of cesarean delivery & $1.73 \pm 0.7474$ & $1.69 \pm 0.749$ & .819 & $>.05$ \\
\hline Estimated gestational age (weeks) & $39.64 \pm 1.32$ & $39.59 \pm 1.27$ & .528 & $>.05$ \\
\hline Time of cesarean delivery & $32.25 \pm 3.83$ & $32.40 \pm 3.80$ & .567 & $>.05$ \\
\hline
\end{tabular}

Table 3 presents the baseline characteristics of hemodynamic variables, including the systolic arterial pressure, the diastolic arterial pressure, and the mean arterial pressure. It was ob- served that, there was a no statistically significant difference between the both groups regarding different hemodynamic values, whereas $p$ value $>.05$.

Table 3. Distribution of base line of hemodynamic variables of mothers under study

\begin{tabular}{|c|c|c|c|c|}
\hline \multirow{2}{*}{ Variable } & Leg compression group $(n=384)$ & Control group $(n=384)$ & \multirow{2}{*}{$\begin{array}{l}\text { Independent } \\
t \text { test }\end{array}$} & \multirow{2}{*}{$p$ value } \\
\hline & Mean \pm SD & Mean \pm SD & & \\
\hline SAP base line (mmHg) & $120.85 \pm 4.62$ & $120.77 \pm 4.59$ & .219 & $>.05$ \\
\hline DAP base line (mmHg) & $76.796 \pm 5.69$ & $76.28 \pm 4.92$ & 1.321 & $>.05$ \\
\hline MAP base line (mmHg) & $93.93 \pm 1.51$ & $94.09 \pm 1.33$ & 1.59 & $>.05$ \\
\hline
\end{tabular}

Note. $\mathrm{SAD}$ = systolic arterial pressure; DAP = diastolic arterial pressure; MAP = mean arterial pressure.

Table 4 reveals the distribution of hypotension among hemodynamic variables, it was pointed out that, hypotension of the systolic arterial pressure, the diastolic arterial pressure, and the mean arterial pressure was affected a greater percentage among mothers at the control group than those in the leg compression group with a highly statistically significant difference between both groups.
Figure 1 shows the distribution of signs of hypotension among the studied mothers in the leg compression and the control group. It was noticed that, both nausea and vomiting as a signs of hypotension were greatly found among mothers at the control group, they were represented as $72.7 \%$ $\& 59.6 \%$ respectively compared to $18.8 \%$ \& $8.9 \%$ among mothers in the leg compression group whereas $p$ value $<$ $.001 * *$.

Table 4. Distribution of hypotension of different hemodynamic studied variables among mothers under study

\begin{tabular}{|c|c|c|c|c|c|c|c|c|c|c|}
\hline \multirow{3}{*}{ Variable } & \multicolumn{4}{|c|}{ Leg compression group $(n=384)$} & \multicolumn{4}{|c|}{ Control group $(n=384)$} & \multirow{3}{*}{$\begin{array}{l}\text { Chi } \\
\text { square }\end{array}$} & \multirow{3}{*}{$p$ value } \\
\hline & \multicolumn{2}{|l|}{ Yes } & \multicolumn{2}{|l|}{ No } & \multicolumn{2}{|c|}{ Yes } & \multicolumn{2}{|c|}{ No } & & \\
\hline & No. & $\%$ & No. & $\%$ & No. & $\%$ & No. & $\%$ & & \\
\hline $\begin{array}{l}\text { Hypotension of systolic } \\
\text { arterial pressure }\end{array}$ & 154 & 40.1 & 230 & 59.9 & 271 & 70.6 & 113 & 29.4 & 72.11 & $<.001^{* *}$ \\
\hline $\begin{array}{l}\text { Hypotension of diastolic } \\
\text { arterial pressure }\end{array}$ & 167 & 43.5 & 217 & 56.5 & 288 & 75.0 & 96 & 25.0 & 78.95 & $<.001^{* *}$ \\
\hline $\begin{array}{l}\text { Hypotension of meanarterial } \\
\text { pressure }\end{array}$ & 143 & 37.2 & 241 & 62.8 & 359 & 93.5 & 25 & 6.5 & 268.33 & $<.001 * *$ \\
\hline
\end{tabular}

** Highly statistical significant difference at $<.001$.

Table 5 manifests the neonatal characteristics among the leg compression and the control group. It was observed that, there was no statistically significant difference regarding neonatal birth weight and neonatal sex among both groups. On the other hand, there was a highly statistically significant difference between two groups in relation to the Apgar score

Published by Sciedu Press

of the neonate at the first minute and the neonatal acidosis ( $p$ $\left.<.001^{* *}\right)$. In addition, there was a statistically significant difference regarding the Apgar score of the neonate at the fifth minute, and admission of the neonate to intensive neonatal care unit. 


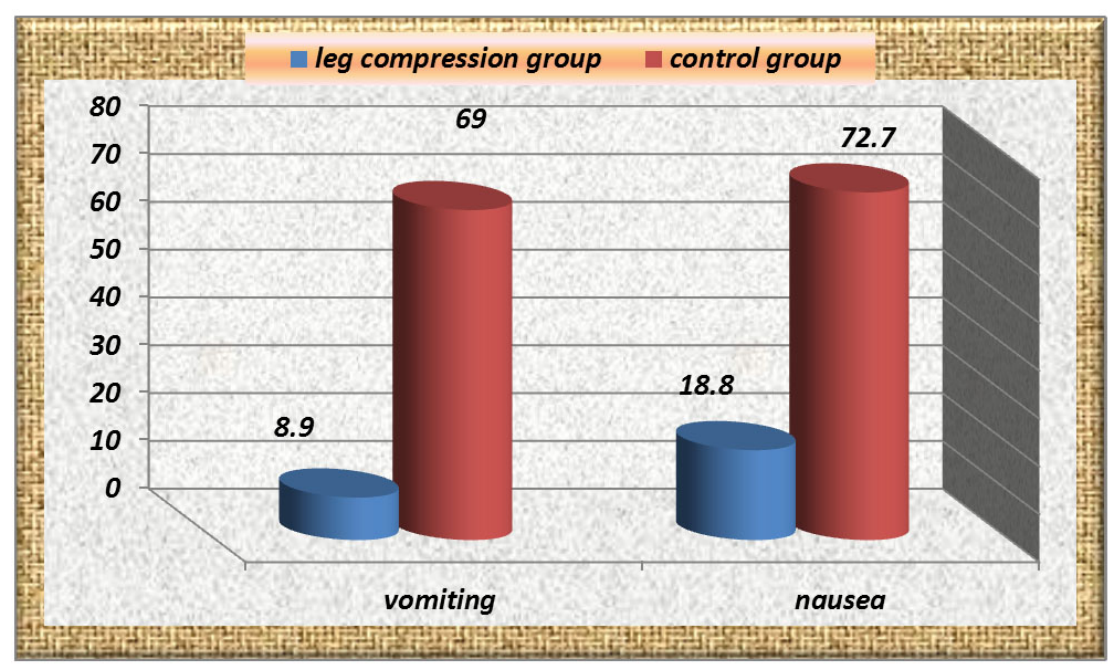

Figure 1. Distribution of nausea and vomiting among mothers under the study

Table 5. Distribution of neonatal characteristics of mothers under study

\begin{tabular}{|c|c|c|c|c|c|c|}
\hline \multirow{2}{*}{ Variable } & \multicolumn{2}{|c|}{ Leg compression group $(n=384)$} & \multicolumn{2}{|c|}{ Control group $(n=384)$} & \multirow{2}{*}{$\begin{array}{l}\text { Chi square } \\
\text { test }\end{array}$} & \multirow{2}{*}{$p$ value } \\
\hline & No & $\%$ & No & $\%$ & & \\
\hline \multicolumn{7}{|c|}{ Neonatal birth weight in (grams) } \\
\hline$<2,500$ & 164 & 42.7 & 178 & 46.4 & & \\
\hline $2,500-$ & 208 & 54.2 & 197 & 51.3 & 1.30 & $>.05$ \\
\hline $3,500-$ & 12 & 3.1 & 9 & 2.3 & & \\
\hline Mean \pm SD & \multicolumn{2}{|c|}{$2,595.44 \pm 356.91$} & \multicolumn{2}{|c|}{$2,577.21 \pm 357.76$} & & \\
\hline \multicolumn{7}{|l|}{ Neonatal sex } \\
\hline Male & 204 & 53.1 & 199 & 51.8 & .131 & $>.05$ \\
\hline Female & 180 & 46.9 & 185 & 48.2 & & \\
\hline \multicolumn{7}{|l|}{ Apgar score at 1 minute } \\
\hline Good (8-10) & 317 & 82.6 & 261 & 68.0 & 22.07 & $<.001 * *$ \\
\hline Moderate asphyxia (5-7) & 46 & 12.0 & 81 & 21.1 & & \\
\hline Sever asphyxia $(\leq 4)$ & 21 & 5.5 & 42 & 10.9 & & \\
\hline \multicolumn{7}{|l|}{ Apgar score at 5 minutes } \\
\hline Good (8-10) & 355 & 92.4 & 335 & 87.2 & 8.47 & $<.05^{*}$ \\
\hline Moderate asphyxia (5-7) & 20 & 5.2 & 24 & 6.3 & & \\
\hline Sever asphyxia $(\leq 4)$ & 9 & 2.3 & 25 & 6.5 & & \\
\hline \multicolumn{7}{|l|}{ Neonatal acidosis } \\
\hline Yes & 56 & 14.6 & 93 & 24.2 & 11.40 & $<.001 * *$ \\
\hline No & 328 & 85.4 & 291 & 75.8 & & \\
\hline \multicolumn{7}{|l|}{ Admission to intensive care } \\
\hline Yes & 29 & 7.6 & 49 & 12.8 & 5.70 & $<.05^{*}$ \\
\hline No & 355 & 92.4 & 335 & 87.2 & & \\
\hline
\end{tabular}

* Statistical significant difference at $<.05 ; * *$ Highly statistical significant difference at $<.001$.

\section{Discussion}

Spinal anesthesia is undoubtedly the most popular technique of anesthesia for cesarean section. However, spinal anesthesia is associated with a high incidence of maternal hy- potension, which can result in fetal distress and maternal discomfort. ${ }^{[15]}$ So, the aim of the present study was to evaluate the effect of the lower leg compression technique for reducing spinal induced hypotension and related risks for 
mothers and neonates during cesarean delivery.

As regards to the effect of the leg compression on reducing spinal induced hypotension during cesarean delivery, the present study findings pointed out that, there was a highly statistically significant difference between the leg compression and the control groups regarding hypotension of the SAP, the DAP, and the MAP. From the point of view of the researcher, spinal anesthesia for cesarean delivery may causes an inadequate venous return, and compressing the legs following spinal anesthesia increases venous return at the time that this is required and at a rate faster than can be achieved by intravenous infusion. The current study findings are in the same line withAdsumell et al. $(2003)^{[16]}$ who conducted a study to evaluate the effect of sequential compression device with thigh-high sleeves supports, they found that, a greater than $20.0 \%$ were reported a decrease in MAP, $52.0 \%$ of patients in the SCD group versus $92.0 \%$ in the control group ( $p=$ .004 , odds ratio $0.094,95 \%$ CI $0.018 \pm 0.488$ ).

In addition, in Egypt, Khedr (2013) ${ }^{[17]}$ carried out a study to evaluate preventive measures to reduce post-spinal anesthesia hypotension for elective cesarean delivery, it was found a significant difference among the groups, as leg wrapped and elevated immediately after anesthesia group had a higher mean systolic arterial pressure (MSAP), lower percentage of hypotension, and lower percentage of bad neonatal outcomes, lower percent of hypotension women late onset time of hypotension .

Moreover, Cyan (2006) ${ }^{[11]}$ conducted a study to assess the effects of prophylactic interventions for hypotension following spinal anesthesia for caesarean section. The study presented that, interventions such as colloids, ephedrine, phenylephrine or lower leg compression can reduce the incidence of hypotension, and none had been shown to eliminate the need to treat maternal hypotension during spinal anesthesia for caesarean section.

The incidence of post-operative nausea and vomiting after spinal anesthesia has remained high and has a major negative impact on patient satisfaction about the overall surgical experience. The present study added that, nausea and vomiting affected the control group more than those in leg compression group. These findings may be related to that, hypotension incidence was high among the control group, which may

\section{REFERENCES}

[1] Klohr S, Roth R, Hofmann T, et al. Definitions of hypotension after spinal anaesthesia for caesarean section: literature search and application to parturients. Acta Anaesthesiol Scand. 2010; 54(8): lead to brain stem ischemia, which is thought to activate the circulatory, respiratory, and vomiting centers grouped together in the medulla. ${ }^{[18]}$

As regards neonatal outcomes, the present study revealed that, there was no statistically significant difference between the leg compression and the control group regarding neonates' weight, and sex. These findings were agreed with Adsumell et al. (2003), ${ }^{[16]}$ who added that, there was no significant difference between the studied groups regarding neonatal birth weight and sex.

In relation to the neonatal condition, as assessed by Apgar scores and umbilical cord blood gases, the present study pointed out that, they were excellent among the leg compression group, and there was a significant difference between both groups. These findings may be related to that uteroplacental circulation and hence fetal wellbeing depends on maternal blood pressure. Spinal anesthesia for caesarean section can cause sudden and severe drops in blood pressure, thus threatening fetal and neonatal acid-base balance. Neonates born to mothers with hypotension are significantly more acidotic than those who don't. These findings are in agreement with Ueyama (2009), ${ }^{[19]}$ who conducted a study to examine the effects of crystalloid and colloid preload on blood volume on the parturient undergoing spinal anesthesia for cesarean section. The researcher noticed that, the maternal hypotension had a strong correlation with neonatal acidemia. In addition, Reynolds and Seed (2005), ${ }^{[20]}$ were added that, there is a positive correlation between anesthesia for caesarean section and neonatal acid-base status.

\section{Conclusion}

Based on the current study findings, it can be concluded that, the lower leg compression for women under elective cesarean with spinal anesthesia is an effective measure to reduce spinal induced hypotension during cesarean delivery and neonatal acidosis.

\section{Recommendations}

The lower leg compression during cesarean delivery should be included in the maternal hospitals' protocol for reducing spinal induced hypotension during cesarean delivery.

\section{Conflicts of InTEREST Disclosure}

The authors declare that there is no conflict of interest.
909-21. PMid:20455872 http://dx.doi.org/10.1111/j.139 9-6576.2010.02239.x

[2] Mercier FJ, Augè M, Hoffmann C, et al. Maternal hypotension during spinal anesthesia for caesarean delivery. Minerva Anestesiol. 2013; 


\section{9: 62-73. PMid:23135692}

[3] Chumpathong S, Chinachoti T, Visalyaputra S, et al. Incidence and risk factors of hypotension during spinal anaesthesia for cesarean section at Siriraj Hospital. Journal of Medical Association of Thailand. 2006; 89(8): 1127-1132. PMid: 17048420

[4] Langesæter E, Dyer RA. Maternal haemodynamic changes during spinal anaesthesia for caesarean section. Curr Opin Anaesthesiol. 2011; 24: 242-8. http://dx.doi.org/10.1097/aco.0b013e3 2834588 c5

[5] Loubert C. Fluid and vasopressor management for Cesarean delivery under spinal anesthesia: Continuing professional development. Can J Anaesth. 2012; 59: 604-19. PMid:22528166 http: //dx.doi.org/10.1007/s12630-012-9705-9

[6] Habib AS. A review of the impact of phenylephrine administration on maternal hemodynamics and maternal and neonatal outcomes in women undergoing cesarean delivery under spinal anesthesia. Anesth Analg. 2012; 114: 377-90. PMid:22104076 http: //dx.doi.org/10.1213/ANE.0b013e3182373a3e

[7] Mohta M, Janani SS, Sethi AK, et al. Comparison of phenylephrine hydrochloride and mephentermine sulphate for prevention of post spinal hypotension. Anaesthesia. 2010; 65: 1200-5. PMid:21182601 http://dx.doi.org/10.1111/j.1365-2044.2010.06559.x

[8] Gunusen I, Karaman S, Ertugrul V, et al. Effects of fluid preload (crystalloid or colloid) compared with crystalloid co-load plus ephedrine infusion on hypotension and neonatal outcome during spinal anaesthesia for caesarean delivery. Anaesth Intensive Care. 2010; 38: 647-53. PMid:20715726

[9] Roofthooft E, Van de Velde M. Low-dose spinal anaesthesia for caesarean section to prevent spinal-induced hypotension. Curr Opin Anaesthesiol. 2008; 21: 259-62. PMid:18458538 http://dx.doi .org/10.1097/AC0.0b013e3282ff5e41

[10] Williamson W, Burks D, Pipkin J, et al. Effect of timing of fluid bolus on reduction of spinal-induced hypotension in patients undergoing elective cesarean delivery. AANA J. 2009; 77: 130-6. PMid:19388508
[11] Cyna AM, Andrew M, Emmett RS, et al. Techniques for preventing hypotension during spinal anaesthesia for caesarean section. Cochrane Database Syst Rev. 2006. http://dx.doi.org/10.10 02/14651858. CD002251.pub2

[12] Dyer RA, Joubert IA. Low-dose spinal anaesthesia for caesarean section. Curr Opin Anaesthesiol. 2004; 17: 301-8. http://dx.doi .org/10.1097/01.aco.0000137088.29861.64

[13] Riley ET, Editorial I. Spinal anaesthesia for Caesarean delivery: Keep the pressure up and don't spare the vasoconstrictors. Br J Anaesth. 2004; 92: 459-61. PMid:15013956 http://dx.doi.org/10.10 93/bja/aeh084

[14] Farruk MA, Aneela P, Vigar A. Prevention of hypotension in cesarean delivery under spinal anaesthesia; the combination of modified supine wedged position, crystalloid co-hydration and prophylactic atropine. Pakistan Armed Forces Medical Journal.

[15] Van Velde M. Spinal anesthesia in the obstetric patient: prevention and treatment of hypotension. Acta Anaesth Belg. 2006; 57: 383-386.

[16] Adsumelli RS, Steinberg ES, Schabel JE, et al. Sequential compression device with thigh-high sleeves sup-ports mean arterial pressure during caesarean section under spinal anaesthesia. Br J Anaesth 2003; 91: 695-8. http://dx.doi.org/10.1093/bja/aeg248

[17] Khedr NF. Preventive Measures to Reduce Post-spinal Anesthesia Hypotension for Elective Cesarean Delivery. Journal of American Science. 2011; 7(2)

[18] David CW. Postoperative Nausea and Vomiting in Regional Anesthesia Anesthesiology; American Society of Anesthesiologists, Inc. Lippincott Williams \& Wilkins(c). 2003; 98: 530-47.

[19] Ueyama H, He YL, TanigamiH, et al. Effects of crystalloid and colloid preload on blood volume in the parturient undergoing spinal anesthesia for elective cesarean section. Anesthesiology. 2009; 91: 1571-6. http://dx.doi.org/10.1097/00000542-199912000-00006

[20] Reynolds F, Seed PT. Anesthesia for Caesarean section and neonatal acid-base status: a meta-analysis. Anesthesia. 2005; 60(7): 633. PMid:15960713 http://dx.doi.org/10.1111/j.1365-2 $044.2005 .04223 . \mathrm{x}$ 